\title{
AISLADA DE OCCIDENTE Y CERCANA A EURASIA: VENEZUELA FRENTE A LA COVID-19 Y EL ORDEN GLOBAL POSPANDEMIA
}

\author{
ISOLATED FROM THE WEST, CLOSE TO EURASIA: \\ VENEZUELA, COVID-19 AND THE POST-PANDEMIC \\ GLOBAL ORDER
}

\section{ISOLÉ DE L'OCCIDENT ET PROCHE DE L'EURASIE: LE VÉNÉZUELA FACE Á LA COVID-19 ET L'ORDRE MONDIAL POST-PANDÉMIE}

\author{
José Briceño Ruiz \\ UNAM CIALC \\ bricenoruiz@unam.mx
}

\begin{abstract}
RESUMEN: El objetivo de este trabajo es analizar la estrategia internacional desarrollada por el régimen de Nicolás Maduro (2013- ) en Venezuela para enfrentar las limitaciones internas en el tratamiento de la pandemia de Covid-19. Se argumenta que, ante la crisis económica y el aislamiento internacional, el gobierno de Maduro necesita la ayuda de China y Rusia, dos potencias revisionistas, para garantizar el tratamiento de la pandemia. Sin embargo, más allá de eso, la política de Venezuela ha implicado un posicionamiento a favor de Rusia y China en la lucha por la construcción de un nuevo orden global. Este proceso se ha acelerado por la pandemia y Venezuela ha adoptado la posición de un Estado revolucionario que se ha sumado a las demandas de estas dos potencias revisionistas respecto a un nuevo orden global.
\end{abstract}

Palabras clave: Venezuela; Covid-19; multilateralismo; China; Rusia.

AbSTRACT: The objective of this paper is to analyze the international strategy developed by the regime of Nicolás Maduro in Venezuela to address its internal limitations in the response to the Covid-19 pandemic. It argues that in the context of an economic crisis and international isolation, Maduro's government needs the aid of China and Russia, two revisionist powers, to deal with the pandemic. Beyond that, however, Venezuela's policy has also involved a positioning in favor of Russia and China in the struggle to build a new global 
order. This process has been accelerated by the pandemic and Venezuela has adopted the position of a revolutionary state that has signed up to the demands for a new global order set out by the two revisionist powers.

Key words: Venezuela; Covid-19; multilateralism; China; Russia.

\section{Traducción de Fionn Petch, CM IDiomas}

Résumé: L'objectif de ce travail est d'analyser la stratégie internationale développée par le régime de Nicolás Maduro (2013- ) au Venezuela pour faire face aux limitations internes dans le traitement de la pandémie Covid-19. Face à la crise économique et à l'isolement international, le gouvernement Maduro a besoin de l'aide de la Chine et de la Russie, deux puissances révisionnistes, pour garantir le traitement de la pandémie. Cependant, au-delà de cela, la politique du Venezuela a impliqué une position en faveur de la Russie et de la Chine dans la lutte pour la construction d'un nouvel ordre mondial. Ce processus a été accéléré par la pandémie et le Venezuela a adopté la position d'un État révolutionnaire qui s'est joint aux revendications de ces deux puissances révisionnistes concernant un nouvel ordre mondial.

Mots clefs: Vénézuela ; Covid19 ; multilatéralisme ; Chine ; Russie.

Traducción de Rafael Segovia, CM Idiomas

Fecha de recepción: octubre de 2020

Fecha de aceptación: marzo de 2021 


\section{INTRODUCCIÓN}

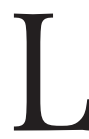

a pandemia de la Covid-19 llega a Venezuela en un momento de crisis estructural de su economía y sus instituciones democráticas. Esta crisis se ha reflejado en el ámbito internacional en un creciente aislamiento de Venezuela en las instancias multilaterales y regionales latinoamericanas y hemisféricas. Por un lado, debido a su desconocimiento por Estados Unidos, la Unión Europea (UE) y el Grupo de Lima, el gobierno de Nicolás Maduro (2013- ) no tiene acceso a recursos del Fondo Monetario Internacional (FMI), el Banco Mundial (Bм) o el Banco Interamericano de Desarrollo (BID), pues al estar controlados por países que reconocen a Juan Guaidó desde enero de 2019 como presidente interino, se bloquea cualquier solicitud de Nicolás Maduro. ${ }^{1}$ Por otro lado, el país está al margen de la mayor parte de las iniciativas regionales para responder a la crisis.

Ante este contexto, el gobierno de Maduro ha reforzado su relación con Cuba, un país con ciertos conocimientos especializados (expertise) en materia de salud, con Rusia y especialmente China. Con estas acciones, Venezuela opta claramente por una estrategia fuera del bloque occidental y de los espacios latinoamericanos, salvo la Alianza Bolivariana para los Pueblos de nuestra América (Alba) y la Comunidad de Estados Latinoamericanos y Caribeños (Celac). Es cierto que

${ }^{1}$ Hugo Chávez amenazó en 2007 con retirarse del FMI, pero esto nunca se cumplió. Ello ha conducido a quienes no están completamente informados de la realidad venezolana a afirmar que el país rompió con el FMI. Venezuela nunca ha dejado de pertenecer a este fondo, de hecho, en 2021 es aún titular de Derechos Especiales de Giro, que son parte de las reservas internacionales de Venezuela. Sólo en 2018 Venezuela retiró 15594863 en Derechos Especiales de Giro (DEG), equivalentes a unos 21.9 millones de dólares. Es cierto que Venezuela no ha solicitado programas de apoyo económico al FMI, pero es errado asimilar eso a una ruptura o retiro. Venezuela tampoco ha dejado de ser miembro del вм. "Venezuela retiró \$21,9 millones del FMI en agosto", Banca y Negocios, 25 de septiembre de 2018. 
las sanciones económicas instauradas por Estados Unidos desde 2017 han contribuido a ese aislamiento y consolidado una "estrategia euroasiática", pero incluso antes de la pandemia era claro el alejamiento de Venezuela de Occidente expresado, por ejemplo, en su retiro de mecanismos del sistema interamericano, como la Corte Interamericana de Derechos Humanos en 2013, la Organización de Estados Americanos (oEA) en 2017 o sus amenazas, nunca cumplidas, de retirarse del BM y FMI.

En ese escenario, parecería que la "estrategia euroasiática" y el continuo apoyo de Cuba eran las únicas opciones que Venezuela tendría para enfrentar la pandemia. Sin embargo, también es válido argumentar que la estrategia internacional para enfrentar la Covid-19 está en concordancia con la política exterior promovida por el gobierno de Venezuela desde 1998, una de cuyas metas principales es enfrentar a Estados Unidos y al mundo occidental. La continuidad de esta política durante la pandemia tiene lugar en el marco de una discusión sobre el impacto de ésta en el orden global. La negativa de Estados Unidos de ser líder durante la crisis y el papel que en su lugar han tomado China y, en menor medida, Rusia, se suman al debate sobre el orden global que ha generado el ascenso de estas dos "potencias revisionistas". En este contexto de transformaciones globales, Venezuela desea posicionarse al lado de estos dos países, que como pay off han estado muy activos brindando ayuda al gobierno de Maduro tanto en la provisión de equipos médicos como en la posible venta de vacunas.

¿Cuáles son las razones por las cuáles Venezuela ha optado por una estrategia de solicitar el apoyo de Rusia y China para enfrentar la crisis de la Covid-19? ¿Es simplemente una política reactiva ante su aislamiento e incapacidad económica para enfrentar la crisis de la pandemia? O, en cambio, ¿se enmarca en una política exterior de enfrentamiento con Estados Unidos que viene de la era de Hugo Chávez y se profundiza en la era de Maduro? En el primer caso, Venezuela sería una víctima de la geopolítica mundial de las grandes 
potencias y ello explicaría su estrategia frente a la Covid-19. En el segundo caso, Venezuela sería un actor o querría ser un actor, aunque modesto y debilitado, en la dinámica de la reconfiguración del orden mundial y regional que se estaría dando en el marco de la pandemia.

Nuestra hipótesis es que la estrategia internacional de Venezuela frente a la Covid-19 responde a su condición de Estado revolucionario en crisis. Como Estado revolucionario, Venezuela ha cuestionado el orden global liderado por Estados Unidos desde los años de gobierno de Hugo Chávez (1999-2013) y ha apoyado el ascenso de China y el resurgimiento de Rusia, estableciendo además cercanas relaciones con estos dos países. Así, Venezuela ha promovido una estrategia de política exterior propia de un Estado revolucionario que busca transformar el orden mundial y ha visto a China y Rusia como aliados, y la pandemia ha consolidado esa estrategia contestataria. Sin embargo, el Estado revolucionario chavista entró en una profunda crisis desde 2013, tras la muerte de Chávez, el ascenso de Maduro y la caída de los precios del petróleo. Esta crisis económica, derivada de años de políticas económicas equivocadas y agravadas por las sanciones, afectó de forma severa el sistema de salud del país y lo dejó en una situación vulnerable para enfrentar el virus. Ante su aislamiento regional y una política exterior de enfrentamiento con Occidente, el gobierno de Maduro decidió apoyarse en sus aliados "euroasiáticos" para evitar el colapso del país. Así, la conducta de Venezuela se explica por factores ideacionales, ligados a la lógica de internacionalización de la revolución, enfrentamiento con Occidente y cuestionamiento del orden global, y materiales, vinculados a la necesidad de gestionar la crisis económica y de salud que generó la pandemia.

Este trabajo se enmarca entonces en el ámbito del análisis de la política exterior de Venezuela. Se trata de un estudio de caso. En su dimensión micro, se analizan las motivaciones de la política exterior de Venezuela en lo relativo a la Covid-19, pero para comprender esta dimensión micro es necesario articularla con los procesos que se están produciendo a nivel 
macro del sistema internacional, en especial el debate sobre el cambio en el orden global. En el nivel micro, institucional o doméstico se destaca la naturaleza del sistema político venezolano, al que se define como un Estado revolucionario, aunque periférico y en crisis. Existe literatura, que se analiza más adelante, sobre el impacto de los Estados revolucionarios en la política internacional al tratar de llevar sus transformaciones más allá de sus fronteras, como es el caso de Venezuela. Ahora bien, se trata de un Estado revolucionario sumido en una profunda crisis económica, que necesita el apoyo externo para su supervivencia. Esto también explica su política frente a la Covid-19, al tener en China y Rusia aliados que han dado apoyo material para gestionar la crisis de salud.

No obstante, las variables domésticas no son suficientes para explicar la estrategia venezolana. Las variables sistémicas son fundamentales. La pandemia ha intensificado el debate sobre un cambio en el orden global, en el cual China y Estados Unidos son los dos principales actores, pero Rusia también tiene un papel. Y todo este proceso encaja de forma adecuada en la estrategia internacional "revolucionaria" de Venezuela, que se pone al lado de los actores revisionistas del orden mundial actual.

En este artículo se adopta una metodología cualitativa, basada en su mayor parte en el análisis de contenido. Esto es especialmente importante cuando se analiza la dimensión sistémica de los cambios en el orden global y su impacto en la estrategia venezolana. El análisis de la dimensión micro, es decir, de la política exterior venezolana, también requiere acudir al análisis de contenido.

Para realizar este análisis el artículo se divide en tres secciones. En la primera de ellas se revisa la literatura sobre el orden global, potencias revisionistas y Estados revolucionarios. En la segunda sección, se analiza el contexto internacional de la estrategia venezolana, caracterizado por la emergencia de potencias revisionistas, como China y Rusia, que han aprovechado la crisis generada por la pandemia para continuar su estrategia de retar al orden global liberal liderado por Esta- 
dos Unidos. En la tercera sección, se examina la estrategia seguida por Venezuela, que como Estado revolucionario busca posicionarse en esta lucha global al lado de las potencias revisionistas, además de obtener ayuda de éstas para enfrentar sus dificultades internas.

\section{REVISIÓN DE LA LITERATURA: ORDEN GLOBAL, POTENCIAS REVISIONISTAS Y ESTADOS REVOLUCIONARIOS}

El tema del orden internacional, orden global u orden mundial ha sido objeto de un amplio debate en la literatura sobre Relaciones Internacionales y se vincula a temas centrales como el cambio en el sistema internacional, el papel de los Estados que defienden el statu quo y los Estados revisionistas que plantean su transformación. Rosenau describe al orden global como arreglos rutinarios en la política mundial. Se trata de acuerdos que "son fundamentales (como la dispersión del poder entre los actores clave, las diferencias jerárquicas entre ellos, las reglas que vinculan sus interacciones y las premisas que comparten sobre el papel de la fuerza, la diplomacia, la cooperación y el conflicto) y algunos son bastante rutinarios (como los procedimientos comerciales, postales y de pasaporte)". ${ }^{2}$ Para Acharya el orden global debe contar con el apoyo de los diversos actores y ello implica que estos participen en su diseño y se sientan representados por él. Un orden global es legítimo en la medida en que represente a amplios segmentos del sistema internacional, no sólo las grandes potencias, sino que incluya "a los más débiles, los recién llegados y los actores regionales y globales emergentes, que pueden tener una comprensión diferente de lo que constituye un orden mundial legítimo y

${ }^{2}$ James N. Rosenau, "Governance, Order, and Change in World Politics", en James N. Rosenau y Ernst-Otto Czempiel (eds.), Governance Without Government: Order and Change in World Politics, Cambridge, University Press, 1992, p. 5. 
eficaz". ${ }^{3}$ No obstante, el orden global no es simplemente un “orden de Estados nación”, sino que en él participan actores transnacionales y transgubernamentales que operan en el sistema internacional.

El orden internacional comienza a ser cuestionado cuando aparecen en el escenario las denominadas potencias revisionistas o Estados revolucionarios. Éstos son dos conceptos que se han desarrollado en la literatura de las Relaciones Internacionales, a veces usados como sinónimos. Morgenthau describe los Estados revisionistas como imperialistas o aquellos "cuya política exterior busca adquirir más poder del que actualmente tiene, a través de un cambio de las relaciones actualmente existentes". ${ }^{4}$ Davidson cuestiona el excesivo énfasis en el poder o seguridad de Morgenthau al definir un Estado revisionista. Para Davidson, el asunto debe centrarse más bien en los valores. Un Estado revisionista sería aquel que busca valores que no disfruta actualmente. Este autor entiende por valores a "cosas valoradas o deseadas". ${ }^{5}$ Esto incluye territorio, estatus, mercados, ideología y la creación o cambio del derecho y las instituciones internacionales. Además, buscaría convertir a otros a su ideología. ${ }^{6}$ Así, para Davidson un Estado revisionista es el que "busca cambiar la distribución de bienes (territorio, estatus, mercados, expansión de la ideología), y la creación o cambio del derecho e instituciones internacionales". ${ }^{7}$

También existe la categoría Estados revolucionarios. Armstrong describe un Estado revolucionario como aquel que busca "cambios fundamentales en los principios con base a

3 Amitav Acharya, Constructing Global Order: Agency and Change in World Politics, Cambridge, University Press, 2018, p. 7.

${ }^{4}$ Hans Morgenthau, Politics among Nations. The Struggle for Power and Peace, Nueva York, Alfred A. Knopf, 1948, p. 21.

5 Jason W. Davidson, The Origins of Revisionist and Status Quo States, Basingstoke, Palgrave Macmillan, 2006, p. 13.

${ }^{6}$ Ibid, p. 13.

${ }^{7}$ Ibid., p. 14. 
los cuales los Estados llevan a cabo sus relaciones entre sî". 8 Halliday, por su parte, argumenta que los Estados revolucionarios consideran la internacionalización de su lucha como parte de la consolidación interna de sus revoluciones. En la dimensión militar, implica ganar aliados afines. Desde el punto de vista económico, la internacionalización supone relaciones de colaboración con nuevos aliados. Y desde una perspectiva ideológica, la necesidad de una revolución también es promover a nivel internacional ideales similares a los que legitiman su propio régimen interno. ${ }^{9}$

No existe en la literatura una distinción clara entre un Estado o potencia revisionista y un Estado revolucionario, pues ambos buscan cambios en el sistema internacional. Se puede argumentar que dos aspectos permiten diferenciar ambas categorías. La primera es que no toda potencia revisionista es un Estado revolucionario. Ejemplo de ello puede ser Estados Unidos luego de la I Guerra Mundial, cuando de alguna manera se inició la transición de la Pax Británica a la Pax Americana. El presidente Woodrow Wilson planteó cambios en el sistema internacional que reflejaban los valores estadounidenses, como la defensa de los Derechos $\mathrm{Hu}$ manos y la necesidad de crear instituciones, como la Liga de las Naciones. Era revisionista, pero no revolucionario. La segunda es que muchos Estados revolucionarios no son potencias revisionistas, es decir, no tienen las capacidades materiales o ideacionales para transformar solos el sistema internacional. La Francia revolucionaria fue al mismo tiempo un Estado revolucionario y una potencia revisionista por su capacidad de influir en el concierto europeo. La Unión Soviética tuvo un papel similar durante la Guerra Fría. No obstante, países como Irán, Siria, Cuba o Venezuela, son Estados revolucionarios, pero no tienen las capacidades para ser potencias revisionistas.

${ }^{8}$ David Armstrong, Revolution and World Order: The Revolutionary State in International Society, Oxford, University Press, 1993, p. 3.

${ }^{9}$ Fred Halliday, Rethinking International Relations, Basingstoke, Palgrave Macmillan, 1994, p. 90. 
Antes de la llegada de la Covid-19 potencias revisionistas como Rusia o China estaban cuestionando el orden global y contaban con el apoyo de Estados revolucionarios como Venezuela. Ese orden fue construido por Estados Unidos después de la II Guerra Mundial. Para John Ikenberry, Estados Unidos se convirtió en el organizador hegemónico y gerente de ese orden. "El sistema político estadounidense -y sus alianzas, tecnología, moneda y mercados- se fusionaron con el orden liberal más amplio". ${ }^{10}$ Ese orden se ha basado en tres principios. El primero es la ideología liberal, tanto en lo económico, que se expresó en políticas de libre mercado, como en lo político, manifiesto en la defensa de la democracia y de ciertos valores que se consideran universales como el Estado de derecho o la defensa de los derechos humanos. El segundo principio es el multilateralismo, que se exteriorizó en la creación de una serie de instituciones responsables de gestionar temas como el comercio, el desarrollo, la defensa, la seguridad o la cultura, algunas de carácter global como la Organización de las Naciones Unidas (ONU) o el Acuerdo General sobre Aranceles y Comercio (GATT) y otras regionales como la Organización del Tratado del Atlántico Norte (oTAN) o la oEA. Finalmente, ese orden era resguardado por un grupo de países que compartían los valores liberales impulsados por Estados Unidos. ${ }^{11}$

Sin embargo, ese orden está siendo cuestionado por dos potencias revisionistas: Rusia y China. Esto está aconteciendo desde antes de la aparición del Coronavirus. Autores como Acharya han alegado que el orden global liberal estadounidense ha colapsado debido a, entre otros factores, su apego a los Estados nación territorialmente delimitados, su sentido de superioridad jerárquica, la construcción de un multilate-

${ }^{10}$ G. John Ikenberry, Liberal Leviathan: The Origins, Crisis, and Transformation of the American World Order, Princeton, Princeton University Press, 2011, p. 2.

${ }^{11}$ Qingming Huang, "The Pandemic and the Transformation of Liberal International Order", Journal of Chinese Political Science, núm. 26, 2021, pp. 3-6. 
ralismo con base en la imagen propia y el surgimiento de poderes emergentes. ${ }^{12}$ Ikenberry considera que la crisis financiera de 2008 y la consecuente recesión global que le siguió fue el inicio de la crisis del orden liberal de la posguerra. La crisis se generó en territorio estadounidense y el país demostró incapacidad para actuar como líder global para proveer estabilidad económica. ${ }^{13}$ La llegada de Donald Trump (2017-2021) al poder ha sido vista como un factor que ha acelerado la crisis del orden global liderado por Estados Unidos. El ataque de Trump al libre comercio, sus críticas a los aliados en Europa y Asia, a las instituciones multilaterales, a la protección del medio ambiente, y la falta de respeto por los Derechos Humanos (violentado en el caso de los migrantes ilegales) o incluso la democracia misma, como se evidencia en el ataque el 6 de enero de 2021 al Capitolio por grupos que apoyaban su narrativa de fraude electoral, evidencian la flaqueza del papel de Estados Unidos como líder del orden global liberal.

Autores como Acharya argumentan que se está configurando un nuevo orden que se caracterizaría por el fin de la unipolaridad. De igual manera, habría nuevos actores, no sólo los países emergentes, sino organizaciones regionales, corporaciones, y grupos empoderados por las redes sociales. En este nuevo orden habría una nueva interdependencia, más allá del comercio, que incluiría las inversiones, las finanzas o las cadenas de valor. Se definiría por la diversidad ideológica, cultural y política. Finalmente, se caracterizaría por riesgos transnacionales, como la Covid-19. ${ }^{14}$

La llegada del Coronavirus tiene un impacto en este cambiante orden global, no sólo en términos de salud, sino también económico y geopolítico. Ha afectado las relaciones entre

${ }^{12}$ Amitav Acharya, The End of the American World Order, Londres, Polity, 2018, pp. 38-40.

13 G. John Ikenberry, op. cit., p. 5.

${ }^{14}$ Amitav Acharya, "The United Nations Managing and Reshaping a Changing World Order", Global Governance, vol. 26, núm. 2, 2020, pp. 227-228. 
los Estados con los actores intergubernamentales y transnacionales. También plantea una discusión sobre si estamos en un momento de cambio en el cual las potencias revisionistas asumen un mayor protagonismo en la política mundial. Finalmente, crea un escenario en que Estados del Sur global, algunos de naturaleza revolucionaria como Venezuela, intentan posicionarse al lado de los poderes revisionistas emergentes.

El conteXto de la estrategia venezolana: La Covid-19, EL "ORDEN LIBERAL ESTADOUNIDENSE" Y EL REVISIONISMO CHINO-RUSO

Para entender la estrategia de un Estado revolucionario periférico en crisis frente a la pandemia, como es el caso de Venezuela, resulta indispensable analizar el contexto internacional que emerge como consecuencia de ésta, caracterizado por la crisis de las instituciones multilaterales, el fortalecimiento del Estado y una relación distinta, al menos durante la pandemia, con ciertos actores transnacionales. A esto se suma la absoluta incapacidad de Estados Unidos de liderar en la crisis, lo que han aprovechado China y Rusia como poderes revisionistas.

Para algunos autores, la crisis del coronavirus conducirá al fin del orden global liberal dirigido por Estados Unidos. Ésta es la opinión de Dunford y Qi, quienes señalan que una de las consecuencias de la pandemia será "un cambio en el centro del sistema mundial hacia Asia y el establecimiento de un sistema multipolar que se basa en los principios de cooperación y el respeto a la soberanía nacional". ${ }^{15}$ Rodrik argumenta que la pandemia ocasionará la profundización de tendencias que venían ocurriendo desde antes de 2020, como el poder económico creciente de China y su transformación

${ }^{15}$ Michael Dunford y Bing Qi, "Global Reset: COVID-19, Systemic Rivalry and the Global Order", Research in Globalization, núm. 2 ,2020, p. 1.100021 
de un país productor de bienes intensivos en mano de obra barata a una nación con capacidad de dominar nuevos espacios tecnológicos, como el 5G. ${ }^{16}$

Sea la continuidad de transformaciones ya iniciadas o un cambio en el centro del poder mundial, el coronavirus está afectando la forma en que se interrelacionan los actores del sistema internacional. Esto va más allá de la lucha entre el poder del statu quo y las potencias revisionistas emergentes. Ha afectado a las instituciones multilaterales y a los actores transnacionales.

Un aspecto central de la pandemia ha sido el fortalecimiento de los Estados que han asumido el liderazgo en el manejo de la crisis, y que se expresa en las cuarentenas, el cierre de fronteras y la prohibición de viajes internacionales. No obstante, esto no debe llevar a la falsa inferencia de que el Estado del realismo clásico vuelve a dominar el escenario internacional. El Estado nunca ha dejado de ser un actor central en el sistema internacional, pero desde hace décadas le ha tocado convivir con las empresas transnacionales (ETN), organizaciones internacionales (OI) y organizaciones no gubernamentales (ONG). Es válido argumentar que la crisis de la Covid-19 ha reposicionado y fortalecido a los Estados frente a esos actores. Éste es, obviamente, un tema para el debate.

Existe una opinión crítica sobre instituciones como la Organización Mundial de la Salud (oms) o la onU. La prestigiosa revista médica The Lancet, en un editorial reciente, señaló que la pandemia "expuso un sistema de gobernanza mundial fragmentado, que no cuenta con las estructuras para coordinar la recolección y el intercambio de los recursos necesarios para combatir las pandemias". ${ }^{17}$ En el caso concreto de la oms, se la ha criticado por: a) haber subestimado la amenaza, b) estar influida por conflicto de intereses y sesgo político; c) no ha-

${ }^{16}$ Dani Rodrik, “¿El COVID-19 reconstruirá al mundo?”, Project Syndicate, 6 de abril 2020.

17 "Global Governance for COVID-19 Vaccines", The Lancet, vol. 395, núm. 10241, 20 de junio de 2020, p. 1883. 
ber aplicado de forma rigurosa el Reglamento Sanitario Internacional (RSI) aprobado por la misma institución en 2005; d) haber respondido con lentitud; e) no disponer de recursos financieros; f) haber dado una respuesta más política que técnica y g) tener planes de preparación para la pandemia mal equipados para prever y resolver los desafíos éticos únicos que puedan surgir durante diferentes brotes de enfermedades infecciosas. ${ }^{18}$ No obstante, la crítica más fuerte fue su incapacidad de respuesta inicial, en particular en la forma como trató el brote inicial en China, acusándosele incluso de estar muy cercana al gobierno de ese país. ${ }^{19}$

La ONU, en particular su Consejo de Seguridad, también ha recibido críticas. $\mathrm{Al}$ menos en cuatro ocasiones, el Consejo ha aprobado resoluciones para considerar problemas de salud como amenazas a la paz y seguridad internacionales. Éste fue el caso de las resoluciones 1308 (2002) y 1983 (2011) sobre el viH/sida, y las resoluciones 2177 (2014) y 2439 (2018) sobre el ébola. Sin embargo, en el caso de la Covid-19, fue apenas el 1 de julio de 2020 cuando se aprobó la resolución 2552 sobre la pandemia ${ }^{20}$. Las diferencias entre la administración estadounidense, cuyos voceros se referían a la Covid-19 como el "virus chino", y el gobierno de Beijing fueron un factor que incidió en esta tardía actuación del Consejo de Seguridad.

En cuanto al papel de los actores transnacionales, existe un espacio para un debate académico. Desde una perspectiva transnacionalista, se estaría en contra de este argumento del fortalecimiento del Estado, señalando por ejemplo las ganancias obtenidas por Amazon por el incremento de las compras en línea o la importancia de empresas farmacéuticas como Pfizer, Moderna o AstraZeneca en la creación de la vacuna

18 Lidia Kuznetzva, "Covid-19: The World Community Expects the World Health Organization to Play a Stronger Leadership and Coordination Role in Pandemics Control”, Frontiers in Public Health, vol. 8, 2020, p. 4.

${ }^{19}$ Sophie Armand, "COVID-19, the UN, and Dispersed Global Health Security”, Ethics E̊ International Affairs, vol. 34, núm. 3, 2020, p. 374.

${ }^{20}$ Ibid., p. 376. 
contra la Covid-19. No obstante, quienes acuden a este argumento olvidan que muchos de estos proyectos, como el de Moderna o AstraZeneca, recibieron un fuerte apoyo del gobierno de Estados Unidos y Gran Bretaña. ${ }^{21}$ El gobierno de Alemania apoyó a Biontech, socio de Pfizer en la elaboración de la vacuna. De igual manera, la vacuna china Cansino fue inicialmente un proyecto conjunto entre Cansino Biologics, una empresa creada en 2009 en la Zona de Desarrollo Económico y Tecnológico de Tianjin, y el Consejo Nacional de Investigaciones del gobierno de Canadá, del que este último se retiró en agosto de 2020. Sinopharm pertenece a la Comisión Estatal para la Supervisión y Administración de los Activos del Estado chino. La vacuna Sputnik V es producida por el Centro Nacional de Investigación de Epidemiología y Microbiología Gamaleya, que depende del Ministerio de Salud del gobierno ruso. En consecuencia, se nota que el Estado ha tenido un papel fundamental en la búsqueda de la vacuna, que es nada menos que el instrumento que puede poner fin a la crisis.

A lo anterior debe sumarse el apoyo que los Estados nación han dado a empresas, muchas de ellas transnacionales, durante la crisis. Esto ha sucedido en el caso de la región Asia Pacífico, donde se dieron estímulos fiscales a la industria de la aviación, severamente afectada por los cierres de aeropuertos y prohibiciones de vuelo, que los ha obligado a

${ }^{21}$ Por ejemplo, Estados Unidos donó 1000 millones de dólares al consorcio de AstraZeneca y la Universidad de Oxford y Gran Bretaña aportó 102 millones de dólares. Moderna recibió de la Autoridad de Investigación y Desarrollo Biomédico Avanzado (Barda, en inglés) 472 millones de dólares. Janssen, del grupo Johnson \& Johnson, recibió 552.6 millones de Barda. Incluso, el laboratorio Biontech, socio de Pfizer en la elaboración de la vacuna, recibió 445 millones de dólares del gobierno alemán. "EE.UU. donó US\$ 1000 millones a AstraZeneca para crear una vacuna", $D W, 21$ de mayo de 2020 ; "Moderna Gets Further $\$ 472$ Million U.S. Award for Coronavirus Vaccine Development", Reuters, 26 de julio de 2020; "Pfizer Vaccine's Funding Came From Berlin, Not Washington", Bloomberg, 9 de septiembre de 2020; "Empresas y Gobiernos financian con 6900 millones la I+D frente al Covid-19”, El País, 27 de mayo de 2020. 
realizar desembolsos de cerca de 35000 millones. Ello condujo a gobiernos como el de Corea del Sur a aprobar préstamos de bajo costo a las aerolíneas por un valor de 240 millones de dólares. El gobierno de Singapur prometió un apoyo de 525 millones, mediante dos planes: un programa de subsidios para poder pagar los salarios de los trabajadores de las aerolíneas y un paquete de apoyo económico para las empresas. ${ }^{22}$ Por ello, más allá de un transnacionalismo simplista, desde el punto de vista académico es válido al menos plantear un debate sobre la forma en que la pandemia ha influido en las relaciones entre los Estados y las empresas transnacionales.

Un aspecto que sin duda la pandemia ha puesto en evidencia es el absoluto desinterés de la potencia del statu quo para coordinar algún tipo de acción internacional concertada para enfrentar la crisis. ${ }^{23}$ Esto contrasta con el activismo

${ }^{22}$ Yipeng Liu, Jong Min Lee y Celia Lee, "The Challenges and Opportunities of a Global Health Crisis: The Management and Business Implications of COVID-19 from an Asian Perspective", Asian Business E Management, 12 de mayo de 2020, pp. 10-11.

${ }^{23}$ Ciertamente, Estados Unidos ha dado ayuda a diversos países en el mundo para luchar contra la Covid-19. Según la Agencia Estadounidense para el Desarrollo Internacional (USAID), el país ha erogado más de 20500 millones de dólares de ayuda a escala global. Sin embargo, no se debe confundir ayuda bilateral con liderazgo global a través de las instituciones multilaterales, como lo hizo Estados Unidos en materia comercial con el impulso de la ronda Uruguay del GATT en la era de Ronald Reagan o en la lucha con el sida durante los gobiernos de Bill Clinton y George W. Bush. El gobierno de Donald Trump fue realmente incapaz de coordinar ninguna acción multilateral para enfrentar la crisis y en vez de ello se enfrentó con la oms. También se negó a ser parte de la iniciativa Covax de la onU. China aprovechó esta falta de acción. Apoyó a la oms con un aporte de 50 millones de dólares. Sobre visiones chinas y estadounidense sobre el tema véase: Gobierno de Estados Unidos, US Agency for Internacional Development, UsAID, "America Acts. Leading the Global Fight against Covid-19”, https://www.usaid.gov/coronavirus (consulta del 18 de noviembre de 2020); La Oficina de Información del Consejo de Estado de la República Popular de China, "Fighting COVID-19: China in Action", 7 de junio de 2020, http://english.scio.gov.cn/whitepapers/2020-06/07/content_76135269.htm (consulta del 18 de noviembre de 2020). 
de las potencias revisionistas, Rusia y China, que han desarrollado una estrategia de cooperación con los países más afectados por la crisis. El liderazgo natural para enfrentar la crisis le correspondía a quien construyó el orden mundial de la posguerra, es decir, Estados Unidos. Este país tradicionalmente se desempeñó como líder en temas de salud mundial, movilizando recursos para apoyar la terapia antirretroviral a las personas que viven con el viH/sida como parte de su programa bilateral Pepfar (Plan de Emergencia del Presidente para el Alivio del sida) y mediante el apoyo a programas multilaterales, por ejemplo. ${ }^{24}$ Sin embargo, la actitud de Trump frente a la pandemia fue desde sus inicios incoherente en el ámbito doméstico, negando su gravedad o no promoviendo el uso de cubrebocas, lo que causó que Estados Unidos se convirtiera en el país con el mayor número de casos y decesos a nivel mundial. Esto daba la imagen de un país incapaz de resolver la crisis. Stephen Walt ha señalado que "el manejo de Trump de la crisis ha sido una debacle vergonzosa desde el principio, a pesar de las repetidas advertencias, pero también era absolutamente predecible”. ${ }^{25}$ Para Walt eso afectó la imagen de Estados Unidos como un país competente. ${ }^{26}$

A esto se suma la falta de liderazgo a nivel internacional de Estados Unidos en la crisis, lo cual se evidenció en primer lugar en una crítica a la oms a la que responsabilizó de ser "sino-centrista", es decir, cómplice de China en esconder la gravedad de la pandemia. El 14 de abril Trump anunció que suspendía los fondos destinados a la financiación de la oms, mientras se revisaba la respuesta de la institución al brote inicial de la Covid-19. Estados Unidos es el mayor contribuyente a la oms de entre 196 países miembros, con aportes que representan el $15 \%$ del presupuesto del organismo. Es-

${ }^{24}$ Joshua W. Busby, "COVID-19: Politics, Inequalities, and Pandemic Understanding the Anemic Global Response to COVID-19", Journal of Health Politics, Policy and Law, vol. 45, núm. 6, 2020, p. 1016.

${ }^{25}$ Stephen Walt, "The Death of American Competence", Foreign Policy, 23 de marzo de 2020.

${ }^{26}$ Loc. cit. 
tados Unidos aportó 400 millones de dólares al presupuesto de la oms en 2019. ${ }^{27}$ Antes de abril, ya había aportado 57.8 millones de dólares al presupuesto de $2020 .{ }^{28}$ El 29 de mayo de ese año, el gobierno de Trump anunció que Estados Unidos terminaba su relación con la oms, y afirmó: "Debido a que no han hecho las reformas solicitadas y muy necesarias, hoy terminaremos nuestra relación con la Organización Mundial de la Salud y se redireccionan esos fondos a otras necesidades urgentes de salud pública en todo el mundo". ${ }^{29}$

Frente a esta incoherencia estadounidense, China se presentaba como un país coherente en lo interno y solidario a escala global. A pesar de ser el centro inicial de la crisis, la aplicación de una severa cuarentena redujo el número de casos. El 18 de marzo de 2020 China anunció cero nuevos casos y el 7 de abril reportó cero muertes por el coronavirus. La cuarentena duró 76 días en Wuhan; se suspendió el 8 de abril. ${ }^{30}$ Así, China se presentaba como un país capaz de resolver de forma eficiente la crisis, aunque lo haya hecho de forma autoritaria.

Alegando este éxito, China se presentó como un país dispuesto a compartir información y experiencia, así como proporcionar suministros y equipos médicos a países gravemente afectados. Para fines de mayo de 2020, China había prestado asistencia a unos 150 países y cuatro organizaciones internacionales y había enviado 29 equipos de expertos médicos a 27 países. ${ }^{31}$ Como lo señalan Campbell y Doshi:

27 Joshua W. Busby, ibid., p. 1018.

28 Dartunorro Clark, "Trump Halts Funding for the World Health Organization”, NBC News, 14 de abril de 2020.

${ }^{29}$ Donald Trump citado en Lauren Egan, "Trump Says U.S. Will Be 'Terminating' Relationship with WHO”, NBC News, 29 de mayo de 2020.

30 Suisheng Zhao, "Rhetoric and Reality of China's Global Leadership in the Context of COVID-19: Implications for the US-led World Order and Liberal Globalization", Journal of Contemporary China, vol. 30, núm. 128, 2021, pp. 233-248.

${ }^{31}$ Michael Dunford y Bing Qi, ibid., p. 6. 
Cuando ningún Estado europeo respondió al llamado urgente de Italia solicitando equipos médicos y equipo de protección, China se comprometió públicamente a enviar 1000 respiradores, 2 millones de máscaras, 100000 respiradores, 20000 trajes de protección y 50000 kits de prueba. China también ha enviado equipos médicos y 250000 máscaras a Irán y suministros a Serbia, cuyo presidente describió la solidaridad europea como "un cuento de hadas" y proclamó: "El único país que puede ayudarnos es China". ${ }^{32}$

China, una potencia revisionista emergente, se ha aprovechado de la crisis generada por la pandemia para seguir mostrando las debilidades del orden global estadounidense. El casi inexistente liderazgo global de Estados Unidos, el débil funcionamiento de la oms y el aparente éxito del modelo autoritario chino han sido utilizados por Beijing para impulsar su posición en la lucha de poder global con la potencia del statu quo.

Rusia también ha aprovechado la crisis de la pandemia para reposicionarse en el orden global emergente. "Moscú ha planteado considerar a la crisis mundial de la Covid-19 como una oportunidad para formar un nuevo orden mundial universalmente compartido". ${ }^{33}$ A diferencia de China, Rusia no ha debido enfrentar los ataques de Trump sobre la pandemia, pero tampoco dispone de los recursos que tiene Beijing. A pesar de ello, Rusia también ha utilizado la ayuda humanitaria como mecanismo para ser un actor global en el tratamiento de la crisis. Así, Moscú ha proporcionado un millón de pruebas SARs-CoV-2, principalmente a los países de la Comunidad de Estados Independientes; ha enviado personal médico militar a Italia y equipo médico, incluyendo ventila-

${ }^{32}$ Kurt M. Campbell y Rush Doshi, "The Coronavirus Could Reshape Global Order China Is Maneuvering for International Leadership as the United States Falters", Foreign Affairs, 18 de marzo de 2020.

${ }^{33}$ Andrei P. Tsygankov, "The Revisionist Moment: Russia, Trump, and Global Transition", Problems of Post-Communism, publicado en línea el 24 de agosto de 2020, p. 2. 
dores, a Estados Unidos. ${ }^{34}$ Sin duda, el tema de la vacuna ha sido el aspecto central de la estrategia rusa. En agosto de 2020, el presidente de la Federación rusa, Vladimir Putin (2000-2008, 2012- ), anunció que Rusia estaba registrando la primera vacuna contra la Covid-19, la Sputnik V. El solo nombre de la vacuna, que es una reminiscencia de la lucha por la hegemonía en el espacio durante la Guerra Fría, ya evidenciaba la visión estratégica que acompañaba su producción.

\section{LA ReSPUESTA de Venezuela A LA PANDEMIA: ¿NECESIDAD, VÍCTIMA DE LA GEOPOLÍTICA O CONTINUIDAD ESTRATÉGICA?}

El escenario de cambios en el orden global es crucial para entender la estrategia de Venezuela frente a la Covid-19. Obviamente, la pandemia llega a Venezuela en uno de los momentos más difíciles en su historia. El país necesitaba con urgencia insumos y equipos médicos, medicamentos y pruebas y, por supuesto, la vacuna. Sin embargo, la crisis económica generada por dos décadas de políticas económicas erradas y los efectos del bloqueo de facto $^{35}$ impuesto por la adminis-

34 Jadwiga Rogoża y Iwona Wiśniewska, "Russia in the Global 'Vaccine Race"”, OSW Commentary, núm. 358 , 2020, p. 6.

${ }^{35}$ El Secretario General de la onu presentó el 15 de julio de 2019 a la Asamblea General de las Naciones Unidas (AGNU) un Informe elaborado por el Relator Especial Idriss Jazairy, titulado Repercusiones negativas de las medidas coercitivas unilaterales en el disfrute de los derechos humanos, en el que se señala: "los bloqueos y las sanciones económicas equivalen a bloqueos de facto" (p. 4). Posteriormente se afirma: "Desde una perspectiva de derechos humanos, las sanciones económicas cuyos efectos prácticos son muy similares a los de un bloqueo en tiempos de guerra plantean una serie de preocupaciones. Estas sanciones pueden entrañar restricciones al disfrute por parte de la población destinataria de una serie de derechos humanos, como el derecho a la alimentación, a la salud y a la libertad de circulación, y los derechos económicos y sociales en general" (p. 7). Uno de los casos que se analiza en el informe es Venezuela. Es decir, en la AGNU se acepta el uso de la expresión bloqueo de facto. Esto ciertamente implica un cambio en lo que se entiende por bloqueo en el derecho internacional clásico, que se asocia a las acciones que impiden que buques entren o salga de un 
tración Trump en enero de 2019 impiden al gobierno de Maduro adquirir esos equipos en los mercados mundiales. Un agravamiento de la pandemia, por ejemplo, escenas similares a las vistas en Guayaquil, Ecuador, de muertos de Covid-19 abandonados en las calles, podrían tener consecuencias imprevisibles en una población ya fatigada por varios años de privaciones. En ese sentido, no es exagerado decir que el régimen se jugaba su supervivencia con la pandemia. Por ello, ante las limitaciones internas derivadas del caos económico, la ayuda externa era crítica y debido a su aislamiento regional y del mundo Occidental, China y Rusia, se convirtieron en aliados necesarios.

país. Esto lo reconoce el informe, sin embargo, en el mismo se señala: "[ ...] estos tecnicismos jurídicos no deberían eclipsar la similitud general entre los efectos de los bloqueos de iure aplicados en tiempos de guerra y los bloqueos de facto aplicados en tiempo de paz, ya que las poblaciones civiles de los países objeto de sanciones sufren estos últimos de igual modo que lo harían con aquellos" (p. 8). En consecuencia, no es engañoso o poco académico usar la expresión bloqueo de facto para describir las sanciones que se aplican con efectos negativos directos en la población. Sea por desconocimiento del derecho internacional público o por posiciones ideológicas preconcebidas, se quiere descalificar este tipo de discusiones, lo que en el fondo valida prácticas unilaterales de las grandes potencias. Esto obviamente no implica suscribir el discurso del gobierno venezolano que responsabiliza al bloqueo de facto de todos los problemas del país, pues lustros de políticas económicas erradas condujeron al desenlace actual. No obstante, la aplicación de una serie de sanciones, que como señala el informe de Jazairy, equivalen a un bloqueo de facto, han agravado la situación. Muy destacados académicos como María Pilar García Guadillo y Ana Ayuso usan la expresión bloqueo para referirse a las sanciones aplicadas por Estados Unidos a Venezuela. El prestigioso diario conservador Financial Times usa también la expresión bloqueo de facto. Sobre este tema véase: Naciones Unidas, Asamblea General, AGNU, Repercusiones negativas de las medidas coercitivas unilaterales en el disfrute de los derechos humanos. Nota del Secretario General, documento A/74/165, Nueva York, 2019; María Pilar García Guadilla, "Venezuela 2020: autoritarismo político y pragmatismo económico", Nueva Sociedad, núm. 287, 2020, pp. 108-120; Ana Ayuso, "International Support for Venezuelan Democracy Process: The Role of the European Union", СІDОв Notes Internationals, núm. 229, 2020; "US Sanctions Are Worsening Venezuela's Agony", Financial Times, 20 de agosto de 2019. 
Sin embargo, más allá de la necesidad de gestionar la crisis, el gobierno de Maduro también ha vinculado su respuesta a la lucha por el cambio en el orden global que se ha radicalizado en la era de la pandemia. Venezuela ha querido ser parte del juego político global, ubicándose al lado de China y Rusia. Una primera aproximación del asunto es considerar que en verdad Venezuela es una víctima de la geopolítica global; que se ha visto atrapada en el conflicto político entre la potencia del statu quo (Estados Unidos) y las dos potencias revisionistas (China y Rusia). Éste es un enfoque incorrecto. Es cierto que se trata de un juego geopolítico, pero Venezuela no es ninguna víctima. Ha querido ser parte de ese juego como un Estado revolucionario que, aunque no tiene las condiciones materiales para cambiar el orden global, sí puede convertirse en un aliado de las potencias revisionistas y dar legitimidad a las demandas de éstas.

Esta estrategia de cuestionamiento del orden internacional ha sido parte de la política exterior de Venezuela desde el ascenso al poder de Chávez en 1999, aunque en sus primeros años tuvo una naturaleza reformista. Sin embargo, a partir de 2004, esa estrategia se radicaliza y toma el carácter antisistémico propia de un Estado revolucionario.

Un objetivo inicial fuertemente destacado por Chávez fue la necesidad de un mundo multipolar, lo que significó el rechazo del orden global posterior a la Guerra Fría basado en la hegemonía estadounidense. Chávez afirmó en 2001: "Debemos luchar contra un mundo unipolar y a favor de un nuevo orden internacional [...] debemos contribuir a la creación de este mundo multipolar. Éste es un objetivo estratégico esencial". ${ }^{36}$ La política exterior venezolana se radicalizó después de 2004. A raíz de la victoria en el referéndum revocatorio de agosto de 2004, en noviembre de ese año se diseñó un "nuevo mapa estratégico". Ésta fue una hoja de ruta para el nuevo periodo de la revolución "bolivariana", en el que se complementó la crítica

36 Hugo Chávez, "Globalización: la enfermedad del nuevo milenio (entrevista)”, Foreign Affairs en español, vol. 1, núm. 3, 2001. 
del unipolarismo con una narrativa antiimperialista. Después de 2004, el gobierno de Venezuela comenzó a describir a Estados Unidos como un "imperio". Esta retórica "antiestadounidense" y "antimperialista" se convirtió en un elemento crucial en la estrategia internacional del gobierno de Chávez.

Eso implicó un esfuerzo por posicionar a Venezuela en el campo de los Estados que desafiaban el orden global posterior a la Guerra Fría. La búsqueda de relaciones más estrechas con China, Rusia o Irán también evidenciaba la decisión de aliarse con los países que promovían un mundo multipolar. Es válido argumentar que Venezuela actuó como un Estado revolucionario.

Maduro ha continuado la estrategia de Chávez. Por lo tanto, la narrativa antiestadounidense, antiimperialista y anticapitalista ha seguido siendo un componente de la política exterior de Venezuela. A pesar de esos esfuerzos de continuidad, la situación es muy diferente. En primer lugar, Maduro no tiene el carisma que tenía su antecesor. En segundo lugar, la caída de los precios del petróleo ha limitado las posibilidades de financiar programas de cooperación para promover los objetivos de política exterior. Por último, después de la evidencia de violaciones de los derechos humanos y el debilitamiento de las instituciones democráticas, la llamada "revolución bolivariana" ha perdido su encanto en sectores de América Latina, el Caribe y el resto del Sur Global.

Esta situación empeoró después de 2015, cuando el ciclo de gobiernos de izquierda terminó en América Latina y Venezuela se aisló cada vez más en la región. La estrategia más agresiva hacia Venezuela promovida por el gobierno Trump, en particular la amenaza de una intervención militar al afirmar que "todas las cartas estaban sobre la mesa", el reconocimiento de Juan Guaidó como presidente interino en enero de 2019 y las sanciones económicas implementadas en 2017 y 2019, que han configurado un bloqueo de facto, también han contribuido al debilitamiento de la presencia venezolana en los asuntos globales. El aislamiento regional y el conflicto con la administración Trump han llevado al gobierno 
venezolano a promover una estrategia de "fortaleza sitiada" 37 y, en ese contexto, las alianzas extrarregionales construidas por Chávez se volvieron cruciales.

Esta breve descripción de la política exterior de la era del chavismo permite excluir el argumento de una victimización geopolítica durante la pandemia, pues implicaría desconocer la estrategia del gobierno venezolano en las últimas dos décadas. El chavismo ha querido convertir a Venezuela en un actor global, con presencia no sólo en América Latina, sino en África y el Medio Oriente, como parte de una estrategia para promover su "revolución bolivariana" y buscar aliados en su conflicto con Estados Unidos. La respuesta a la pandemia de la Covid-19 se inserta en esta estrategia desarrollada durante décadas.

La diferencia en la era de Maduro es que esta estrategia revolucionaria se ha tenido que combinar con una política exterior que ayude a la sobrevivencia del régimen. Por ejemplo, la relación con Irán, que se profundiza a partir de 2003, tenía la meta de encontrar en Teherán un socio para enfrentar a Estados Unidos. En la era de Maduro, Irán es un aliado para la sobrevivencia del régimen, como se expresó en el envío de gasolina en junio 2020, cuando el país carecía del producto. Eso también se aplica a la Covid-19. Venezuela se pone al lado de China y Rusia en la lucha por el orden global, pero también necesita que ellos le envíen mascarillas, insumos médicos, asistencia médica o vacunas que permitan evitar un recrudecimiento de la pandemia con potenciales efectos negativos en la estabilidad del gobierno.

Venezuela y las instancias multilaterales

Durante sus dos décadas de existencia, el chavismo criticó duramente al FMI. Por ejemplo, en octubre de 2008, Chávez seña-

37 Dmitry M. Rozental y Víctor L. Jeifets, "Política exterior de Venezuela en el ambiente de inestabilidad”, Iberoamérica, núm. 4, 2018, p. 61. 
ló que el FMI debía "disolverse y desaparecer del mundo"38 y anunció su decisión de retirar a Venezuela de esta institución, ${ }^{39}$ aunque al final la amenaza no se cumplió. Esto continuó en la era de Maduro, quien en octubre de 2019 aseveró: "el Fondo Monetario Internacional es el instrumento del mismísimo demonio en el mundo, y es el instrumento para imponer el modelo económico de explotación neocolonial a los pueblos del sur, de los pueblos de América Latina y el Caribe". ${ }^{40}$

A pesar de estas reiteradas críticas, el 15 de marzo de 2020, Maduró envió una carta a Kristalina Georgieva, directora gerente del FMI, en la que señala: "acudimos a su honorable organismo para solicitarles su evaluación respecto a la posibilidad de otorgarle a Venezuela una facilidad de financiamiento por 5000 millones dólares del Instrumento de Financiación Rápida del Fondo (IFR), recursos que contribuirán significativamente para robustecer nuestros sistemas de detección y respuesta". ${ }^{41}$ La petición fue rechazada dos días después, cuando un portavoz del FMi afirmó que: "Lamentablemente, el Fondo no está en condiciones de considerar esa solicitud", ${ }^{42}$ añadiendo que: "el compromiso del FMI con los países miembros se basa en el reconocimiento oficial del Go-

38 "Presidente Chávez: 'El FMI debe desaparecer del mundo'”, Aporrea, 8 de octubre de 2008.

39 "Chávez anuncia la salida de Venezuela del fmi y del Banco Mundial”, El País, 30 de abril de 2007.

40 "Maduro afirma que no es tiempo de atacar a la oms en medio de la pandemia", Sputnik News, 21 de septiembre de 2020, https://mundo.sput niknews.com/politica/202009211092846611-maduro-afirma-que-no-estiempo-de-atacar-a-la-oms-en-medio-de-la-pandemia/ (consulta del 22 de octubre de 2020).

41 "Carta de Nicolás Maduro a Kristalina Georgieva, Directora General del Fondo Monetario Internacional, 15 de marzo de 2020", Twitter del canciller venezolano Jorge Arreaza, @jaarreaza, 17 de marzo de 2020, https:// twitter.com/jaarreaza/status/1239977222271893504 (consulta del 22 de octubre de 2020).

42 Citado en "El FMI rechaza el pedido de 5000 millones de dólares de Venezuela por el coronavirus", EFE, 17 de marzo de 2020. 
bierno por la comunidad internacional, como se refleja en la membresía del FMI. No hay claridad sobre el reconocimiento en ese momento". ${ }^{43}$

Es difícil creer que la respuesta del FMI haya sorprendido a alguien, dentro y fuera del gobierno de Maduro. Aunque es una mera conjetura, es de imaginarse que la carta debió sorprender a los funcionarios de la institución, porque provenía de un país que había mostrado pocas señales de amistad y porque quizá fue una carta enviada sabiendo de antemano la respuesta, debido a la cuestión del reconocimiento de Guaidó. ¿Por qué Maduro envió esa carta? ¿Fue una nueva acción errática del presidente venezolano o fue parte de una estrategia? Existen razones para suponer que fue parte de una estrategia de victimización de su gobierno y culpabilización de las instituciones internacionales por el impacto negativo que la pandemia tuviese en Venezuela. Barrera Tyszka, en un artículo que publicó en The New York Times, sostiene que: "La única respuesta probable a estas preguntas parece encontrarse en el terreno de la comunicación, de la construcción de narrativas y de la producción de sentido. Se trata, por cierto, del ámbito donde el chavismo ha sido siempre más eficaz" ${ }^{44}$ Para Barrera Tyzska, se busca crear una narrativa en la cual Maduro se presenta como un líder dispuesto a renunciar incluso a sus postulados ideológicos para salvar al pueblo venezolano. El régimen chavista "pretende utilizar la urgencia para acorralar a la comunidad internacional" y señalar como responsables de la crisis al FMI, la comunidad internacional y la oposición. ${ }^{45}$

Ésa fue la respuesta efectivamente. Tras conocer de la negativa del FMI, el 19 de marzo Maduro afirmó: "Si hay que ir hasta el mismo infierno para pedir ayuda para Venezuela, lo haré”. En La Habana, en el Diario Oficial Granma, se brindó apoyo inmediato a su aliado en Caracas. En un artículo publi-

${ }^{43}$ Loc. cit.

${ }^{44}$ Alberto Barrera Tyszka, "Venezuela: una emergencia en emergencia”, The New York Times, 22 de marzo de 2020.

${ }^{45}$ Loc. cit. 
cado por el columnista Capote, se cuestionó por qué el FMI apoyó de forma incondicional al gobierno de Mauricio Macri en la Argentina, con fondos "destinados a salvar vidas, a enfrentar la pandemia", ${ }^{46}$ y se negó a dar dinero a Venezuela. Concluye señalando que "el 'instrumento del mismísimo demonio', como bien llamó Maduro al FMI, no está concebido para brindar ayuda desinteresada, es una herramienta de colonización, de dominio imperial". ${ }^{47}$

Sin embargo, no todas las instituciones internacionales cerraron la puerta al régimen de Caracas. Maduro también solicitó a Tedros Adhanom Ghebreyesus, director de la oms, ayuda humanitaria especial, en concreto el envío de kits de pruebas para detectar el coronavirus, insumos, asistencia y cooperación técnica. Para la vicepresidenta Delcy Rodríguez (2018- ), esta ayuda era necesaria porque Venezuela estaba en "una condición especial, porque somos un país ilegalmente sancionado, criminalmente bloqueado", ${ }^{48}$ y señaló que mantener esa agenda política en medio de la pandemia era "realmente miserable y de muy bajas perspectivas humanas". ${ }^{49}$ Como es sabido, la onu reconoce a Maduro como presidente de Venezuela y la oms es una agencia de ésta. A pesar de sus limitaciones debido a su conflicto con el gobierno de Trump y el hecho de tener que brindar asistencia a todos sus países miembros, especialmente en el Sur global, la oms no sólo ha provisto la ayuda solicitada por el gobierno venezolano, sino que ha reconocido como válidas las cifras de casos y decesos ofrecidas por el régimen de Maduro.

${ }^{46}$ Raúl Antonio Capote, "Préstamo del FMI: ¿por qué a la Argentina de Macri sí y a la Venezuela revolucionaria no?”, Diario Granma, 18 de marzo de 2020.

47 "Maduro acusa al FMI de ser un instrumento del 'mismísimo demonio"', Sputnik News, 10 de octubre de 2020, https:/ / mundo.sputniknews.com/ america-latina/201910101088942537-maduro-acusa-al-fmi-de-ser-un-ins trumento-del-mismisimo-demonio/ (consulta del 20 de octubre de 2020).

${ }^{48}$ Citada en "Organización Mundial de la Salud prestará ayuda humanitaria especial a Venezuela para enfrentar Covid-19”, Xinhua, 19 de marzo de 2020.

${ }^{49}$ Loc. cit. 
Sin embargo, en medio de esta discusión aparentemente centrada en el tema de la salud, en el fondo está el conflicto de Estados Unidos con China mencionado líneas arriba. En su participación virtual en la 75 Asamblea General de la ONU, el presidente Xi Jinping (2013- ) aseveró:

[...] la oms ha hecho una importante contribución al liderar e impulsar la respuesta mundial a la Covid-19. Su buena labor es aplaudida por la comunidad internacional. En esta coyuntura crucial, apoyar a la oms es apoyar también la cooperación internacional y la batalla por salvar vidas. China hace un llamamiento a la comunidad internacional para que aumente el apoyo político y financiero a la oms con el fin de movilizar recursos en todo el mundo para derrotar al virus. ${ }^{50}$

En este conflicto, Venezuela se posiciona al lado de China y la oms y así, en mayo de 2020, Maduro planteó al Movimiento de Países no Alineados proponer a la oms como candidata al Premio Nobel de la Paz. En ese mismo discurso, rechazó la politización de la pandemia y abogó por una "nueva geopolítica mundial" basada en "la cooperación, la solidaridad y el multilateralismo", y el rechazo a "la amenaza del uso de la fuerza, el uso de la fuerza y las sanciones unilaterales". ${ }^{51}$ En septiembre, en su discurso ante la Asamblea General de la onU, defendió de nuevo a la oms "como expresión del multilateralismo en un área fundamental de la vida de los pueblos, que es la salud; sobre todo en esta época de pandemia en que la oms ha tenido que soportar ataques, agresiones e insultos". ${ }^{52}$

Se observa entonces que en el ámbito multilateral, el margen de acción del gobierno de Maduro es limitado. Por un

${ }^{50}$ Xi Jinping citado en Riyaz Khaliq, "Defensa de China en la oms: 'El coronavirus no respeta fronteras", Agencia Anadolu, 19 de mayo de 2020.

${ }^{51}$ Nicolás Maduro citado en "Maduro propone a la oms para el Nobel de la Paz", Expansión, 4 de mayo de 2020.

${ }^{52}$ Nicolás Maduro citado en "Maduro afirma que no es tiempo de atacar a la oms en medio de la pandemia", Sputnik News, 21 de septiembre de 2020 . 
lado, no tiene acceso a las instancias financieras como el FMI o incluso el BID, lo que hace muy difícil enfrentar sus restricciones fiscales generadas por la caída en los precios del petróleo, las sanciones de Estados Unidos y la crisis económica que se profundizó mucho más a raíz de la pandemia. Estas limitaciones fiscales también le impiden adquirir los equipos, insumos y medicamentos para enfrentar a la Covid-19. Por otro lado, sí tiene el apoyo de la oms, que ha enviado equipos y suministros e incluso elaboró un Plan Intersectorial de Preparación y Atención Covid-19 Venezuela. ${ }^{53}$ Sin embargo, este apoyo no es suficiente para aminorar los efectos de la crisis y Caracas lo ha aprovechado para ponerse al lado de China y la oms en su conflicto con Estados Unidos.

\section{Las alianzas euroasiáticas: China y Rusia y la estrategia venezolana}

Frente al acceso limitado a las instituciones multilaterales y su aislamiento regional, la estrategia del gobierno venezolano ha sido profundizar sus relaciones con China y Rusia. La relación con China comenzó a desarrollarse ya en el mandato de Chávez, lo que se expresó en una serie de acuerdos económicos, inversiones y préstamos de ese país. ${ }^{54}$ En la era de Maduro, en 2014 se firmó una Alianza Estratégica pero, a partir de 2016, China había disminuido de forma relativa su presencia en Venezuela. La pandemia ha reactivado la relación bilate-

53 Naciones Unidas, Oficina de Coordinación de Asuntos Humanitarios de las Naciones Unidas, OCHA, "Plan Intersectorial de Preparación y Atención Covid-19 Venezuela”, 2020, https://reliefweb.int/sites/reliefw eb.int/files/resources/ven_covid-19_plan_intersectorial_2a_edicion_041 02020.pdf (consulta del 15 de enero de 2021).

54 Sobre las relaciones chino-venezolanas véase José Briceño Ruiz y Norbert Molina Medina, "China-Venezuela Relations in a Context of Change”, en Raúl Bernal-Meza y Li Xing (eds.), China-Latin America Relations in the 21st Century. The Dual Complexities of Opportunities and Challenges, Londres, Palgrave Macmillan, 2020, pp. 147-168. 
ral. China fue el primer país en enviar ayuda médica e insumos a Venezuela y este país participa en la fase III de una de las vacunas chinas. También se ha producido un acercamiento estratégico a Rusia, que se ha profundizado en la era de Maduro. ${ }^{55}$ La aproximación a estos dos países fue parte de una estrategia de diversificación de las relaciones internacionales como un mecanismo para establecer un equilibrio en las conflictivas relaciones con Estados Unidos. ${ }^{56}$

La crisis de la Covid-19 se ha aprovechado para consolidar la relación con estas dos potencias revisionistas, las cuales, por su parte, han desplegado una fuerte diplomacia de salud para posicionarse como líderes mundiales en la lucha contra la pandemia. En este sentido, la ayuda brindada por China a los países del Sur global es parte de una estrategia para aprovechar el vacío de liderazgo dejado por la administración Trump y consolidarse como la potencia mundial en el orden global pos-Covid. En el caso de Rusia, se enmarca en la estrategia de Putin de volver a colocar a su país en el estrado de las potencias globales.

En el caso de Maduro, incluso antes de la llegada de la pandemia a Venezuela, ya manifestaba su apoyo a China frente a los ataques por su tratamiento inicial a la pandemia. El 28 de febrero, Maduro describió a la Covid-19 como "un arma de guerra biológica contra China". ${ }^{57}$ Cuando el virus ingresa al territorio venezolano y ante el fracaso de la sorpresiva solicitud de apoyo al FMI y su aislamiento regional, Caracas dirige su mirada a Beijing para solicitar ayuda, sin la cual no podría hacer frente a la crisis debido a la extrema debilidad de

${ }^{55} \mathrm{Al}$ respecto, véase Adriana Boersner y Makram Haluani, "Convergencias y divergencias en la asociación estratégica ruso-venezolana y sus implicaciones hemisféricas", Cuadernos del CENDES, vol. 30, núm. 82, 2013, pp. 67-107.

${ }^{56}$ Véase Víctor Mijares, "Soft Balancing the Titans: Venezuelan Foreign-Policy Strategy toward the United States, China, and Russia”, Latin American Policy, vol. 8, núm. 2, 2017, pp. 201-231.

${ }^{57}$ Iván Pérez Sarmenti, "Nicolás Maduro sobre el coronavirus: ‘Es arma

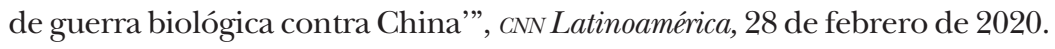


su sistema hospitalario. La respuesta no tardó en llegar. China ha enviado desde marzo varios cargamentos de ayuda humanitaria, que incluye cubrebocas, medicamentos, reactivos, lentes protectores, trajes de bioseguridad, ventiladores, purificadores de aire para los centros de salud. De igual manera, China envió en abril un equipo de médicos especialistas para brindar asistencia técnica y formar a médicos venezolanos en el tratamiento de la pandemia. En octubre de 2020, Maduro anunció la participación de Venezuela en la fase 3 de pruebas de una de las vacunas que se está desarrollando en China.

Esta ayuda humanitaria fue acompañada por acciones políticas dirigidas a resaltar la robustez de la relación bilateral chino-venezolana y destacar el papel de líder solidario desempeñado por China durante la pandemia. En una conversación telefónica entre Xi Jinping y Nicolás Maduro, el 10 de abril de 2020, el líder chino señaló que su país sentía "como propias las dificultades y desafíos que enfrenta Venezuela". ${ }^{58}$ Igualmente, aseveró que las medidas adoptadas por el presidente, a las que describió como oportunas, demostraban "el liderazgo del presidente Maduro ante la comunidad internacional". ${ }^{59}$ Finalmente, Xi reiteró el apoyo chino al gobierno y pueblo venezolanos "en la salvaguardia de la soberanía nacional, el mantenimiento de la estabilidad social y la mejora del bienestar del pueblo". ${ }^{60}$ Se observa entonces que la ayuda humanitaria se fusiona con un discurso político de apoyo al cuestionado régimen de Caracas, lo que fue un claro respaldo en momentos de incertidumbre tras el rechazo del FMI a la solicitud de financiamiento. Ejemplo de esto fueron las declaraciones de la vicepresidenta Rodríguez en marzo de 2020, al recibir el primer cargamento de ayuda, cuando describió la actitud de china como de solidaridad y señaló que "mientras vemos voces aisladas en el mundo, que reflejan la

58 "Maduro y Xi Jinping acuerdan más cooperación para enfrentar la pandemia", EFE, 10 de abril de 2020.

${ }^{59}$ Loc. cit.

60 "Xi: China está lista para continuar ayudando a Venezuela a combatir la Covid-19", Xinhua, 11 de abril de 2020. 
miseria, que pretenden tomar esta pandemia global, en una agenda política, discriminatoria, selectiva, criminal, contra el pueblo venezolano, vemos también esta muestra, que representa el espíritu que debe impregnar a la humanidad entera" ${ }^{6} 1$ En esta aparente alusión a Estados Unidos, el gobierno venezolano vuelve a utilizar su narrativa de un país agredido por los centros del poder mundial y la ayuda china sería un ejemplo del nuevo orden global solidario por construir.

La relación chino-venezolana frente a la Covid-19 es parte del juego geopolítico de ambos países, para China como una potencia revisionista, para Venezuela como un Estado revolucionario en crisis. Ninguno de los dos es víctima, ambos son agentes. China se presenta como un país solidario y comprometido con el multilateralismo en materia de salud que a través de su "diplomacia de mascarillas" provee ayuda material y además asistencia técnica a países del Sur Global cuyos sistemas de salud están en crisis. Venezuela es uno de ellos, pero en la narrativa de Caracas tal crisis obedece a las sanciones impuestas por el gobierno estadounidense, que ni siquiera aceptó suspender estas últimas durante la pandemia. Así, frente al aislamiento regional, el discurso de una víctima acorralada que ayudada por China logra controlar de forma eficiente la Covid-19 es crucial en el intento de reposicionar al régimen en el escenario internacional.

Algo similar sucede en la relación con Rusia. Desde el punto de vista político, ambos países coinciden en temas como la construcción de un orden multipolar, el fortalecimiento de las instituciones internacionales y la demostración de su poder militar. ${ }^{62}$ Existían otras razones para la profun-

${ }^{61}$ Delcy Rodríguez citada en Leonardo Ojeda, "Arriban a Venezuela 4 mil kits de diagnóstico para el Covid-19 provenientes de China", Ministerio del Poder Popular para Relaciones Internacionales, MPPRE, 19 de marzo de 2020.

62 Alexandra Sitenko, "Latin American Vector in Russia's Foreign Policy: Identities and Interests in the Russian-Venezuelan Partnership", Politics in Central Europe, vol. 12, núm. 1, 2016, p. 45. 
dización de las relaciones entre Caracas y Moscú. Algunas de ellas son diferentes a las existentes con China, aunque otras eran similares. Así como China quería vender sus bienes manufacturados a Venezuela, Rusia quería vender sus armas. En otras palabras, la dimensión comercial era importante para las dos potencias revisionistas. Las dificultades de Venezuela de acceder a la compra de armas debido a la negativa de Estados Unidos hicieron de Rusia un potencial socio. Sin embargo, la dimensión política es mucho más fuerte en la relación con Rusia, especialmente a partir de 2014 cuando el enfrentamiento ruso con Estados Unidos se acrecienta debido a la crisis en Ucrania. Ambos países fortalecen sus relaciones económicas, pero Rusia ve en Venezuela la posibilidad de replicar las acciones estadounidenses en Crimea. Si Estados Unidos podía intervenir en la tradicional zona de influencia rusa, Moscú lo podía hacer en América Latina. Venezuela por su parte recibe préstamos rusos en un momento en que se cierra su acceso a los mercados financieros globales, especialmente a partir de las sanciones de 2017, y consolida su relación con una potencia revisionista que se convierte en un aliado en su conflicto con Estados Unidos.

No es sorpresa entonces que Rusia también haya sido un aliado durante la pandemia. El 20 de abril Maduro tuvo una conversación telefónica con el presidente ruso. En un comunicado de prensa que el canciller Jorge Arreaza (2017- ) difundió a través de su cuenta de Twitter, se señala que en la conversación se acordó realizar esfuerzos conjuntos para tratar la pandemia. Rusia habría ofrecido "millares" de pruebas diagnósticas para la Covid y el envío de insumos y materiales de salud. Rusia, que también es objeto de sanciones por parte de Estados Unidos desde 2014, recordó su propuesta ante el Grupo de los 20 (G-20) de permitir los denominados "pasillos verdes", que permitan a los países sometidos a sanciones o guerras comerciales adquirir suministros médicos durante la pandemia. Se planteó entonces "que los países 
afectados puedan tener acceso libre a sus fondos y cuentas internacionales para enfrentar el Covid-19."63

Efectivamente, Rusia ha enviado varios cargamentos de ayuda, en particular conteniendo kits con pruebas de despistaje de la Covid-19. En agosto, la empresa Rosoboronexport S.A., especializada en productos y servicios militares, proveyó un cargamento humanitario con pruebas rápidas de producción rusa para detectar el virus. ${ }^{64}$ Ya más recientemente, Venezuela se incorporó en la fase 3 de prueba de la vacuna Sputnik V, y a inicios de octubre llegó un primer lote de vacunas para ser aplicadas a voluntarios venezolanos. Maduro ha planteado incluso la elaboración de la vacuna rusa en Venezuela, así como la china y la cubana. ${ }^{65}$

De nuevo se observa acá una jugada geopolítica. El acercamiento a Rusia inicialmente se enmarcó en la búsqueda de materiales e insumos, pero con el planteamiento de los "pasillos verdes", se incorporó un elemento crítico a la política de sanciones unilaterales de Estados Unidos. Un tema mayor es el ingreso de Venezuela en la carrera por la vacuna. No parece realista que Venezuela participe en la elaboración de la vacuna por la crisis de su sistema de ciencia y tecnología, pero si se destaca una narrativa contraria a la de un país colapsado, que pretende ser reemplazada por una en la que es capaz de ser parte de iniciativas para desarrollar la vacuna que pondría fin a la crisis global.

La producción de la vacuna es la más reciente etapa en la batalla de poder que está ocurriendo en medio de la pandemia. El que produzca primero la vacuna no necesariamente será el líder del mundo post Covid, pero si gozará de una

${ }^{63}$ República Bolivariana de Venezuela, "Comunicado", 20 de abril de 2020, https://www.analitica.com/actualidad/actualidad-nacional/putin-ymaduro-conversan-sobre-esfuerzos-para-luchar-contra-el-coronavirus/ (consulta del 22 de octubre de 2020).

64 "Rosoboronexport prestó a Venezuela la ayuda humanitaria para luchar contra Covid-19”, Rosoboronexport, 19 de agosto de 2020.

65 "Venezuela afirma que formalizó solicitudes para producir vacuna contra el Covid-19”, Diario Digital Nuestro País, 20 de septiembre de 2020. 
mayor fortaleza y prestigio. En parte el apresurado impulso ruso en posicionarse en esta carrera, usando incluso un nombre que rememora la carrera espacial (Sputnik), es expresión de esa búsqueda de tener una posición de mayor poder en el sistema internacional. Venezuela apuesta por estos proyectos.

\section{Conclusiones}

La crisis de la Covid-19 evidencia la estrategia de un gobierno colapsado en lo económico y sanitario, y aislado de su región para encontrar ayuda y cooperación. Su limitado acceso a las instancias multilaterales y su exclusión de la mayor parte de los procesos de integración y cooperación regional en el continente americano lo ha llevado a consolidar sus alianzas con Rusia y China. Además de obtener un apoyo material sin el cual seguramente hubiese entrado en una crisis sanitaria aún mayor, la estrategia tiene claros objetivos internacionales. Venezuela se ha sumado a las potencias revisionistas, China y Rusia, que impulsan un cambio en el orden global y han utilizado la pandemia para evidenciar su creciente liderazgo. Ante la incapacidad de la administración Trump, estas dos potencias revisionistas han desplegado acciones de cooperación médica en Europa, África, Asia y América Latina. Venezuela, un Estado revolucionario periférico en crisis, también ha aprovechado la pandemia para reposicionarse en el sistema internacional y apoyar a sus socios revisionistas. Diversos factores explican esta estrategia. Por un lado, está un elemento ideacional o simbólico en su enfrentamiento contra Estados Unidos, la uE y el Grupo de Lima que consiste en presentarse como un país acosado por las "potencias capitalistas", que no le permiten usar sus recursos económicos bloqueados, no admite pasillos verdes en medio de la crisis e impiden que se le preste asistencia financiera en el FMI. Bajo esta perspectiva, no hay responsabilidad de Maduro. La crisis no es resultado de años de políti- 
cas económicas erradas, corrupción y abandono del sistema de salud; es resultado de la agresión externa. Por otro lado, al acudir al respaldo de China y Rusia, confirma en medio de la pandemia su posición en la batalla por el liderazgo en el orden global que se viene dando en los últimos lustros. Reitera su enfrentamiento a la administración de Trump, se posiciona en defensa de la oms e insiste en construir un nuevo orden mundial contrario al liberalismo, en el cual, por supuesto, China sería el líder. Así, la ayuda es parte de un juego de poder y en China, como en Estados Unidos, se entiende así también. En ese nuevo orden, Rusia sería de nuevo una potencia global. ${ }^{66}$

Es posible que esta estrategia haya ayudado a que la crisis interna no empeorara. Aunque se haya utilizado una estrategia autoritaria y existan dudas sobre la confiabilidad de los datos del gobierno, el hecho es que en Venezuela no se observa un desborde de los casos como se suponía podría suceder debido a la crisis de su sistema de salud. En parte, esto obedece a la ayuda chino-rusa. No obstante, a nivel internacional se muestra un país aislado y con un número de aliados, aunque poderosos, limitado. El intento de obtener asistencia financiera del FMI o el histriónico relanzamiento del Alba, anunciando un Fondo Humanitario para el cual no existen recursos, es muestra de un esfuerzo para presentarse como un país activo en la política global y regional, pero limitado en sus resultados. En el caso del Alba, expresa un intento de

${ }^{66} \mathrm{Si}$ Rusia es ya una potencia global es algo que se discute en la literatura sobre el tema. Aunque ciertamente su influencia geopolítica ha crecido de forma amplia desde 2014, el pequeño tamaño de su economía, su presencia militar limitada en otras regiones del mundo e incluso su relativo atraso tecnológico plantean dudas. La estrategia de Vladimir Putin durante la crisis de la Covid-19 ha sido justamente demostrar que el país sí es una potencia global, al punto de ser el primero en anunciar que había desarrollado una vacuna. Al respecto, véase Andrei Melville, Andrei Akhremenko y Mikhail Mironyuk, "What Russia Can Teach Us about Power and Influence in World Politics", Russian Politics, vol. 4, núm. 2, 2019, pp. 137-167. 
mostrarlo como un bloque que desea ejercer un liderazgo solidario en el tratamiento de la pandemia. Ello en nada modifica la profunda crisis que la población venezolana viene sufriendo desde hace ya varios años y que se ha agravado con la pandemia de la Covid-19.

\section{REFERENCIAS BibLIOGRÁFICAS}

Acharya, Amitav, "The United Nations Managing and Reshaping a Changing World Order”, Global Governance, vol. 26, núm. 2, 2020, pp. 221-235.

Acharya, Amitav, Constructing Global Order. Agency and Change in World Politics, Cambridge, University Press, 2018.

Acharya, Amitav, The End of the American World Order, Londres, Polity, 2018.

Armand, Sophie, "COVID-19, the UN, and Dispersed Global Health Security”, Ethics E̊ International Affairs, vol. 34, núm. 3, 2020, pp. 373-378.

Armstrong, David, Revolution and World Order: The Revolutionary State in International Society, Oxford, University Press, 1993.

Ayuso, Ana, "International Support for Venezuelan Democracy Process: The Role of the European Union", СІров Notes Internationals, núm. 229, 2020.

Barrera Tyszka, Alberto, "Venezuela: una emergencia en emergencia”, The New York Times, 22 de marzo de 2020, https:// www.nytimes.com/es/2020/03/22/espanol/opinion/coronavirus-venezuela.html (consulta del 22 de octubre de 2020).

Boersner, Adriana y Makram Haluani, "Convergencias y divergencias en la asociación estratégica ruso-venezolana y sus implicaciones hemisféricas", Cuadernos del CENDES, vol. 30, núm. 82, 2013, pp. 67-107.

Briceño Ruiz, José y Norbert Molina Medina, "China-Venezuela Relations in a Context of Change", en Raúl Bernal-Meza y Li Xing (eds.), China-Latin America Relations in the 21 $1^{\text {st }}$ Century. The Dual Complexities of Opportunities and Challenges, Londres, Palgrave Macmillan, 2020, pp. 147-168. 
Busby, Joshua W., "COVID-19: Politics, Inequalities, and Pandemic Understanding the Anemic Global Response to COVID-19", Journal of Health Politics, Policy and Law, vol. 45, núm. 6, 2020, pp. 1013-1021.

Campbell, Kurt M. y Rush Doshi, "The Coronavirus Could Reshape Global Order China is Maneuvering for International Leadership as the United States Falters", Foreign Affairs, 18 de marzo de 2020, https://www.foreignaffairs.com/articles/chi na/2020-03-18/coronavirus-could-reshape-global-order (consulta del 18 de noviembre de 2020).

Capote, Raúl Antonio, "Préstamo del fmi: ¿por qué a la Argentina de Macri sí y a la Venezuela revolucionaria no?", Diario Granma, 18 de marzo de 2020, http:/ / www.granma.cu/mundo/2020-0318/ prestamo-del-fmi-por-que-a-la-argentina-de-macri-si-y-a-lavenezuela-revolucionaria-no-18-03-2020-23-03-23 (consulta del 22 de octubre de 2020).

"Carta de Nicolás Maduro a Kristalina Georgieva, Directora General del Fondo Monetario Internacional, 15 de marzo de 2020", Twitter del canciller venezolano Jorge Arreaza, @jaarreaza, 17 de marzo de 2020, https://twitter.com/jaarreaza/status/ 1239977222271893504 (consulta del 22 de octubre de 2020).

"Chávez anuncia la salida de Venezuela del FMI y del Banco Mundial”, El País, 30 de abril de 2007, https://elpais.com/econo$\mathrm{mia} / 2007 / 05 / 01 /$ actualidad/1178004773_850215.html (consulta del 22 de octubre de 2020).

Chávez, Hugo, "Globalización: la enfermedad del nuevo milenio (entrevista)", Foreign Affairs en español, vol. 1, núm. 3, 2001.

Clark, Dartunorro, "Trump Halts Funding for the World Health Organization", $N B C$ News, 14 de abril de 2020, https:/ /www.nbc news.com/politics/white-house/trump-says-he-halting-fund ing-world-health-organization-n1183941 (consulta del 15 de noviembre de 2020).

Davidson, Jason W., The Origins of Revisionist and Status Quo States, Basingstoke, Palgrave Macmillan, 2006.

"EE.UU. donó US\$ 1.000 millones a AstraZeneca para crear una vacuna", DW, 21 de mayo de 2020, https://www.dw.com/es/ee- 
uu-don \% C3\% B3-us-1000-millones-a-astrazeneca-para-crearuna-vacuna/a-53523935 (consulta del 15 de febrero de 2021). EgAN, Lauren, “Trump Says U.S. Will Be 'Terminating' Relationship with WHO”, NBC News, 29 de mayo de 2020, https://www.nbc news.com/politics/white-house/trump-says-u-s-will-be-termi nating-relationship-who-n1218441 (consulta del 15 de noviembre de 2020).

"El FMI rechaza el pedido de 5000 millones de dólares de Venezuela por el coronavirus", EFE, 17 de marzo de 2020, https://www. efe.com/efe/america/economia/el-fmi-rechaza-pedido-de5-000-millones-dolares-venezuela-por-coronavirus /20000011-4 198313 (consulta del 22 de octubre de 2020).

"Empresas y gobiernos financian con 6900 millones la I+D frente al Covid-19", El País, 27 de mayo de 2020, https:/ / cincodias.elpa is.com/cincodias/2020/05/27/companias/1590594780_188 420.html (consulta del 15 de febrero de 2021).

García Guadilla, María Pilar, "Venezuela 2020: autoritarismo político y pragmatismo económico", Nueva Sociedad, núm. 287, 2020, pp. 108-120.

"Global Governance for COVID-19 Vaccines", The Lancet, vol. 395, núm. 10241, 20 de junio de 2020, p. 1883.

Gobierno de Estados Unidos, Agencia Estadounidense para el Desarrollo Internacional, usAID, "America Acts. Leading the Global Fight against Covid-19”, https://www.usaid.gov/coronavi rus (consulta del 18 de noviembre de 2020).

Halliday, Fred, Rethinking International Relations, Basingstoke, Palgrave Macmillan, 1994.

Ikenberry, G. John, Liberal Leviathan: The Origins, Crisis, and Transformation of the American World Order, Princeton, University Press, 2011.

KhaliQ, Riyaz, "Defensa de China en la oms: 'El coronavirus no respeta fronteras'”, Agencia Anadolu, 19 de mayo de 2020, https:// www.aa.com.tr/es/pol\%C3\%ADtica/defensa-de-china-en-laoms-el-coronavirus-no-respeta-fronteras/1845782\# (consulta del 22 de octubre de 2020).

Kuznetzva, Lidia, "Covid-19: The World Community Expects the World Health Organization to Play a Stronger Leadership and 
Coordination Role in Pandemics Control", Frontiers in Public Health, vol. 8, 2020, art. 470.

"Maduro acusa al FMI de ser un instrumento del "'mismísimo demonio'”, Sputnik News, 10 de octubre de 2020, https:/ / mundo. sputniknews.com/america-latina/201910101088942537-ma duro-acusa-al-fmi-de-ser-un-instrumento-del-mismisimo-demo nio/ (consulta del 20 de octubre de 2020).

"Maduro afirma que no es tiempo de atacar a la oms en medio de la pandemia”, Sputnik News, 21 de septiembre de 2020, https:/ / mundo.sputniknews.com/politica/202009211092846611-ma duro-afirma-que-no-es-tiempo-de-atacar-a-la-oms-en-medio-dela-pandemia/ (consulta del 22 de octubre de 2020).

"Maduro y Xi Jinping acuerdan más cooperación para enfrentar la pandemia", EFE, 10 de abril de 2020, https:/ / www.efe.com/efe/ america/politica/maduro-y-xi-jinping-acuerdan-mas-coopera cion-para-enfrentar-la-pandemia/20000035-4218427 (consulta del 22 de octubre de 2020).

"Maduro propone a la oms para el Nobel de la Paz", Expansión, 4 de mayo de 2020, https://www.expansion.com/agencia/europa press/2020/05/04/20200504183039.html (consulta del 22 de octubre de 2020).

Melville, Andrei, Andrei Akhremenko y Mikhail Mironyuk, "What Russia Can Teach Us about Power and Influence in World Politics", Russian Politics, vol. 4, núm. 2, 2019, pp. 137-167.

Mijares, Víctor, "Soft Balancing the Titans: Venezuelan ForeignPolicy Strategy toward the United States, China, and Russia", Latin American Policy, vol. 8, núm. 2, 2017, pp. 201-231.

"Moderna Gets Further \$472 Million U.S. Award for Coronavirus Vaccine Development”, Reuters, 26 de julio de 2020, https:// www.reuters.com/article/us-health-coronavirus-moderna-fund ing-idUSKCN24R0IN (consulta del 15 de febrero de 2021).

Morgenthau, Hans, Politics among Nations. The Struggle for Power and Peace, Nueva York, Alfred A. Knopf, 1948.

Naciones Unidas, Asamblea General, AGNU, Repercusiones negativas de las medidas coercitivas unilaterales en el disfrute de los derechos humanos. Nota del Secretario General, documento A/74/165, Nueva York, 2019. 
Naciones Unidas, Oficina de Coordinación de Asuntos Humanitarios, OCHA, "Plan Intersectorial de Preparación y Atención Covid-19 Venezuela", 2020, https://reliefweb.int/sites/reliefweb. int/files/resources/ven_covid-19_plan_intersectorial_2a_edi cion_04102020.pdf (consulta del 15 de enero de 2021).

Oficina de Información del Consejo de Estado de la República Popular de China, "Fighting COVID-19: China in Action", 7 de junio de 2020, http:/ / english.scio.gov.cn/whitepapers/2020-06/ 07/content_76135269.htm (consulta del 18 de noviembre de 2020).

OJEDA, Leonardo, "Arriban a Venezuela 4 mil kits de diagnóstico para el Covid-19 provenientes de China", Ministerio del Poder Popular para Relaciones Internacionales, MPPRE, 19 de marzo de 2020, http:/ / mppre.gob.ve/2020/03/19/arriban-venezuela-4-milkits-diagnostico-covid-19-china/ (consulta del 22 de octubre de 2020).

"Organización Mundial de la Salud prestará ayuda humanitaria especial a Venezuela para enfrentar COVID-19", Xinhua, 19 de marzo de 2020, http:/ /spanish.xinhuanet.com/2020-03/19/_ 138894218.htm (consulta del 22 de octubre de 2020).

Pérez SARMenti, Iván, "Nicolás Maduro sobre el coronavirus: 'Es arma de guerra biológica contra China'”, CNN Latinoamérica, 28 de febrero de 2020, https://cnnespanol.cnn.com/video/ venezuela-nicolas-maduro-coronavirus-arma-de-guerra-con tra-china-perspectivas-buenos-aires/ (consulta del 22 de octubre de 2020).

"Pfizer Vaccine's Funding Came From Berlin, Not Washington", Bloomberg, 9 de septiembre de 2020, https:/ /www.bloomberg. $\mathrm{com} /$ news/articles/2020-11-09/pfizer-vaccine-s-funding-camefrom-berlin-not-washington (consulta del 15 de febrero de 2021).

"Presidente Chávez: 'El FMI debe desaparecer del mundo'”, Aporrea, 8 de octubre de 2008, https://www.aporrea.org/actuali$\mathrm{dad} / \mathrm{n} 121992 . h t m l$ (consulta del 22 de octubre de 2020).

QIngming, Huang, "The Pandemic and the Transformation of Liberal International Order", Journal of Chinese Political Science, núm. 26, 2021, pp. 1-26. 
República Bolivariana de Venezuela, "Comunicado", en "Putin y Maduro conversan sobre esfuerzos para luchar contra el coronavirus", Analítica, 20 de abril de 2020, https://www.analitica. $\mathrm{com} /$ actualidad/actualidad-nacional/putin-y-maduro-conver san-sobre-esfuerzos-para-luchar-contra-el-coronavirus/ (consulta del 22 de octubre de 2020).

RoDrik, Dani, “¿El Covid-19 reconstruirá al mundo?”, Project Syndicate, 6 de abril 2020, https://www.project-syndicate.org/ commentary/will-covid19-remake-the-world-by-dani-rodrik2020-04/spanish?barrier=accesspaylog (consulta del 20 de octubre de 2020).

RogożA, Jadwiga y Iwona Wiśniewska, "Russia in the Global 'Vaccine Race'”, OSW Commentary, núm. 358, 2020, pp. 1-6.

Rosenau, James N., "Governance, Order, and Change in World Politics”, en James N. Rosenau y Ernst-Otto Czempiel (eds.), Governance Without Government: Order and Change in World Politics, Cambridge, University Press, 1992, pp. 1-29.

"Rosoboronexport prestó a Venezuela la ayuda humanitaria para luchar contra Covid-19", Rosoboronexport, 19 de agosto de 2020, http://roe.ru/esp/zona-de-prensa/press-releases/roso bo ronexport-prest-a-venezuela-la-ayuda-humanitaria-para-luchar -contra-covid-19/?from_main (consulta del 22 de octubre de 2020).

Rozental, Dmitry M. y Víctor L. Jeifets, "Política exterior de Venezuela en el ambiente de inestabilidad", Iberoamérica, núm. 4, 2018, pp. 53-76.

Sitenko, Alexandra, "Latin American Vector in Russia's Foreign Policy: Identities and Interests in the Russian Venezuelan Partnership", Politics in Central Europe, vol. 12, núm. 1, 2016, pp. 37-51.

Suisheng, Zhao, "Rhetoric and Reality of China's Global Leadership in the Context of COVID-19: Implications for the US-led World Order and Liberal Globalization", Journal of Contemporary China, vol. 30, núm. 128, 2021, pp. 233-248.

Tsygankov, Andrei P., "The Revisionist Moment: Russia, Trump, and Global Transition", Problems of Post-Communism, 24 de agosto de 2020, p. 2, https://www.tandfonline.com/doi/pdf/10.10 
80/10758216.2020.1788397?needAccess=true (consulta del 18 de noviembre de 2020).

"US Sanctions Are Worsening Venezuela's Agony", Financial Times, 20 de agosto de 2019, https://www.ft.com/content/f7dd72a4c044-11e9-b350-db00d509634e (consulta del 15 de febrero de 2021).

"Venezuela afirma que formalizó solicitudes para producir vacuna contra el Covid-19”, Diario Digital Nuestro País, 20 de septiembre de 2020, https://www.elpais.cr/2020/09/20/venezuelaafirma-que-formalizo-solicitudes-para-producir-vacuna-contrael-covid-19/ (consulta del 22 de octubre de 2020).

"Venezuela retiró \$21,9 millones del FMI en agosto", Banca y Negocios, 25 de septiembre de 2018, https://www.bancaynegocios. com/venezuela-retiro-219-millones-del-fmi-en-agosto/ (consulta del 15 de febrero de 2021).

WALt, Stephen, "The Death of American Competence", Foreign Policy, 23 de marzo de 2020, https:/ / foreignpolicy.com/2020/03/ 23/death-american-competence-reputation-coronavirus / (consulta del 20 de noviembre de 2020).

"Xi: China está lista para continuar ayudando a Venezuela a combatir COVID-19", Xinhua, 11 de abril de 2020, http:/ /spanish. xinhuanet.com/2020-04/11/c_138965601.htm (consulta del 22 de octubre de 2020).

Yipeng, Liu, Jong Min Lee y Celia Lee, "The Challenges and Opportunities of a Global Health Crisis: The Management and Business Implications of COVID-19 from an Asian Perspective", Asian Business $\mathcal{E} \mathcal{O}$ Management, publicado en línea el 12 de mayo de 2020, pp. 10-11 1-21, https://www.ncbi.nlm.nih.gov/pmc/ articles/PMC7216126/ (consulta del 15 de febrero de 2021). 
